\title{
Assessment Of Anxiety In Patients Attending Baqai Dental Teaching Hospital Karachi-A Cross Sectional Study
}

Aisha Wali, Syed Abrar Ali, Talha M Siddiqui, Mahnoor Farzand, Laraib Malik

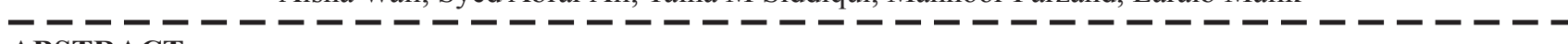
ABSTRACT:

Objective: The objective of the present study was to assess the anxiety levels in patients visiting Dental teaching Hospital by using Corah Dental anxiety scale. (DAS)

Methodology: A cross-sectional study was conducted on patients attending Out Patient Department of Oral Diagnosis Baqai Dental College between June 2017 - Jan 2018. A simple random sampling technique was used for the study purpose. The sample population included patients attending OPD of Oral Diagnosis Department for routine dental checkups, scaling, filling, root canal treatment and extraction. Descriptive statistics were obtained and the mean standard deviation was calculated. Chi-square test was done to compare association of dental anxiety among male and female patients visiting Baqai Dental College. Data was analyzed using SPSS software (Statistical Package for the Social Sciences, Version22).

Results: Based on severity of dental anxiety, 46.4\%, 34.8\% and 15.2\% males were found to be moderately, highly and extremely anxious respectively whereas $53.6 \%, 65.2 \%$ and $84.8 \%$ females were found to be moderately, highly and extremely anxious.

Conclusion: The present study concluded that female patients were found to be more anxious than males. Therefore dental surgeons should take adequate measures to manage level of dental anxiety amongst patients visiting dental teaching hospitals of Karachi.

Key Words: Corah’s Dental Anxiety Scale, Dental anxiety, Fear, Phobia

\section{INTRODUCTION:}

Dental anxiety is defined as an unpleasant complexed emotional state of anxiousness related to an expected encounter associated with a stimulus of fear ${ }^{1}$. It is often stated as a cause of irregular dental visits, delayed pursuing dental treatment or even avoidance of dental treatment ${ }^{2}$ and therefore leading to worsen oral health. ${ }^{3,4}$ Worldwide dental anxiety is considered to be one of the utmost commonest type amongst several other types of anxieties. ${ }^{5,6}$. Mehrstedt et $\mathrm{al}^{7}$ and Crofts-Barnes et al ${ }^{8}$ have reported that those experiencing high levels of dental anxiety are amongst those with the poorest oral health related quality of life. B Mehboob ${ }^{9}$ showed $27 \%$ of the patients were found to be dental phobic.

But the findings of another study revealed that dental

I Aisha Wali,

I Assistant Director, Head of Research Department,

Baqai Dental College.

I Email: aishawali@hotmail.com

Syed Abrar Ali,

I Associate Professor,

I Department of Operative Dentistry,

Hamdard University Dental Hospital

Talha M Siddiqui,

Associate Professor, Head of Department of Operative Dentistry I Baqai Dental College

1

Mahnoor Farzand

House surgeon

I Baqai Dental College

I Laraib Malik,

I House surgeon

Baqai Dental College

Received: 05-10-18

Accepted: 13-11-18 anxiety was reported only among $3 \%$ percent of the patients ${ }^{10}$.

Gender, age, objects and situations are possible factors of dental anxiety ${ }^{6}$. It has also been observed in various studies that dental instruments could be one of the main reason for causing dental anxiety when it is placed in a mouth results in gag reflex ${ }^{11}$.

Regarding gender, females have been consistently identified as having high levels of dental anxiety when compared to male patients ${ }^{12}$. Hagglin $\mathrm{C}$ et al ${ }^{13}$ conducted a research on middle-aged and elderly women and reported that both dental anxiety and regular dental attendance declines with increasing age. The oral health of dentally anxious women who visited the dentist regularly was better than those who visits irregularly ${ }^{14}$. Z Morse $^{15}$ revealed that anxiety was greatly experienced by females and in individuals undergoing dental extraction. Stabholz A et $\mathrm{al}^{16}$ showed that females were very anxious when undergoing Root canal treatment ${ }^{16}$. Poor oral hygiene results in shame and avoidance for the patients to visit the dentist and seeks dental treatment only when experiences pain with unbearable symptoms ${ }^{17}$. Dentists must assess levels of patient's anxiety in order to provide quality treatment. Lower levels of anxiety is managed by creating a friendly environment and reassuring the patient. Similarly moderate levels of anxiety was managed by coping strategy whereas pharmacological management is necessary for extremely phobic/ anxious patients ${ }^{18}$. The rationale of the present study was to assess dental anxiety in adult patients and their association with age, gender, past dental history and frequency of dental visits. Dental anxiety has a widespread effect on an individual's personality and therefore it is of utmost importance for dental surgeons to identify anxious patients and manage them accordingly. 
Aisha Wali, Syed Abrar Ali, Talha M Siddiqui, Mahnoor Farzand, Laraib Malik

\section{METHODOLOGY:}

A cross-sectional study was conducted on patients attending Out Patient Department of Oral Diagnosis Baqai Dental College between June 2017 to Jan 2018. The Ethical Committee of Baqai Medical University approved the study design and all the respondents were provided to sign a detailed consent form.

A simple random sampling technique was used for the study purpose. The sample population included patients who attended Out Patient Department of Oral Diagnosis Department for routine dental checkups, scaling, filling, root canal treatment and extraction. Patients who had impacted teeth, severe periodontal disease and with the history of anxiety disorders were excluded from the study. The sample size was calculated by taking $50 \%$ prevalence rate and computed using Open Epi version 3.03a at 95\% confidence interval and $\mathrm{a}=5 \%$. The sample size calculated was 384 . The questionnaire consisted of two sections. The first section included the demographic profile and the second section included the Dental Anxiety Scale (DAS). The questionnaire included four questions that were used to measure the anxiety level due to certain dental procedures and situations. These include the following:

a) If you had to go to the dentist tomorrow for a checkup, how would you feel about it?

b) When you are waiting in the dentist's office for your turn in the chair, how do you feel?

c) When you are in the dentist's chair waiting while the dentist gets the drill ready to begin working on your teeth, how do you feel?

d) Imagine you are in the dentist's chair to have your teeth cleaned. While you are waiting and the dentist or hygienist is getting out the instruments which will be used to scrape your teeth around the gums, how do you feel?

Each question has five points Likert responses. These responses range from relaxed coded as 1 to so anxious coded as $5^{19}$. Assessment of the level of anxiety is calculated by summation of points of scale items as following: lowest score 8 means no anxiety, 9 - 12 means moderate anxiety, $13-14$ means high anxiety, and $15-20$ means severe anxiety/ phobic ${ }^{20}$.

Descriptive statistics were obtained and the mean standard deviation was calculated. Chi-square test was done to compare association of dental anxiety among male and female patients visiting Baqai dental college. Data was analyzed using IBM SPSS software (Statistical Package for the Social Sciences, Version22).

\section{RESULTS:}

The sample consisted of 144 males and 240 females aged $18-35$ years. Based on severity of dental anxiety, $46.4 \%$, $34.8 \%$ and $15.2 \%$ males were found to be moderately, highly and extremely anxious respectively whereas 53.6\%, 65.2\% and $84.8 \%$ females were found to be moderately, highly and extremely anxious. A statistically significant association was found between gender and levels of anxiety ( $p$-value 0.000 ). Mean DAS was found to be 2.73. (Table 1). Seventy $(83.3 \%)$ of the female respondents and $14(16.7 \%)$ of males were very anxious when asked about the visit scheduled for next day. Forty six $(90.2 \%)$ of females and $5(9.8 \%)$ of males were very anxious about waiting for the turn on dental chair. Twenty nine $(82.9 \%)$ of the females and $6(17.1 \%)$ of males were found to be very anxious about waiting for turn to get the teeth drilled. Twenty seven $(93.1 \%)$ of the females and $2(6.9 \%)$ of males were very anxious about their teeth to be cleaned. (Table 2).

\section{DISCUSSION:}

Fear is considered to be an inevitable thrilling, a response to some external stimuli in which individual is afraid without clear reasons ${ }^{21}$. The result of the present study was done to assess the level of dental anxiety in patients visiting dental teaching hospital. Karachi. Levels of dental anxiety was calculated by using Corah's Dental Anxiety Scale. The present study reported mean DAS to be 2.73 in a sample of patients attending dental teaching hospital. Anzar $\mathrm{W}^{22}$ in a study reported mean DAS to be 9.3 in local sample population of Karachi. Olszewska et $\mathrm{al}^{23}$ calculated mean Dental Anxiety Score (DAS) to be around 10.5 in their study on Krakow's residents. Iqbal $\mathrm{M}$ in a study reported that mean score for DAS was $8.74^{24}$.

In this present study females were found to be more anxious than males. Results from this study reported that 106(84.8\%) of females were found to be severe anxious and 19(15.2\%) males severely anxious. $16(27.6 \%)$ of the females and $42(72.4 \%)$ of males were found to be not anxious. Wahid $\mathrm{U}$ et $\mathrm{al}^{25}$ in a study reported that $24(9.3 \%)$ of the female respondents were found to be severely anxious, 9(7.4\%) highly anxious, $127(49.2 \%)$ moderately anxious and $88(34.1 \%)$ non anxious. Six $(4.8 \%)$ of the male respondents were found to be severely anxious, $61(48.8 \%)$ moderately anxious and 58(46.4\%) non anxious.

Jafarzadeh et $\mathrm{al}^{26}$ in a study showed that females were found to be more anxious than males. Anzar $\mathrm{W}^{22}$ in a study reported that females were more anxious as compared to men. Similar findings were reported by Stabholz A et $\mathrm{al}^{27}$, Malvania ${ }^{28}$, Cristospher et al. ${ }^{29}$ Sardar KP et $\mathrm{al}^{30}$ in a study also reported that females were found to be more anxious than males. The reason behind is the difference in brain chemistry of male and female as the fright and flight response in females are more readily active partly due to action of estrogen and progesterone $^{31}$.

Corah's Dental Anxiety Scale consists of 4 items with 5 point Likert responses ${ }^{19}$. The first item was related to patients' anxiety level that was scheduled for the next day. Iqbal $\mathrm{M}^{24}$ in a study reported that $100(43.5 \%)$ of the respondents were 


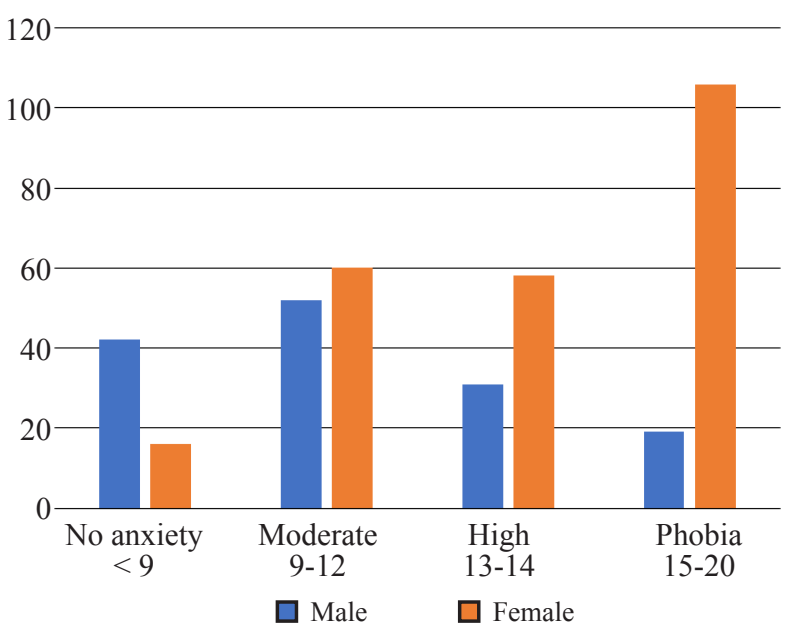

\begin{tabular}{|l|c|c|c|}
\hline \multicolumn{1}{|c|}{ DAS Items } & $\mathrm{n}$ & Mean \pm SD & Mean DAS \\
\hline $\begin{array}{l}\text { Anticipation for checkup for } \\
\text { the next day }\end{array}$ & 384 & $3.63 \pm 1.112$ & \\
\cline { 1 - 3 } Waiting in the dentist office & 384 & $3.06 \pm 1.238$ & \multirow{2}{*}{2.73} \\
\cline { 1 - 3 } $\begin{array}{l}\text { Waiting for the dentist to start } \\
\text { drilling of tooth }\end{array}$ & 384 & $2.99 \pm 1.146$ & \\
\cline { 1 - 3 } $\begin{array}{l}\text { Waiting for the dentist to clean } \\
\text { the teeth }\end{array}$ & 384 & $3.04 \pm 1.116$ & \\
\hline
\end{tabular}

Table 1: Descriptive study (Mean and standard deviation of DAS)

Figure 1: levels of Dental anxiety scale amongst patients

\begin{tabular}{|l|c|c|c|c|c|}
\hline & Gender & Item 1 & Item 2 & Item 3 & Item 4 \\
\hline \multirow{3}{*}{ Relaxed } & Male & $20(80 \%)$ & $35(68.6 \%)$ & $29(69 \%)$ & $29(76.3 \%)$ \\
\cline { 2 - 6 } & Female & $5(20 \%)$ & $16(31.4 \%)$ & $13(31 \%)$ & $9(23.7 \%)$ \\
\hline \multirow{2}{*}{ A little uneasy } & Male & $18(54.5 \%)$ & $42(53.2 \%)$ & $47(51.1 \%)$ & $45(51.1 \%)$ \\
\cline { 2 - 6 } & Female & $15(45.5 \%)$ & $37(46.8 \%)$ & $45(48.9 \%)$ & $43(48.9 \%)$ \\
\hline \multirow{3}{*}{ Tense } & Male & $41(47.7 \%)$ & $36(35.3 \%)$ & $45(40.2 \%)$ & $40(37.4 \%)$ \\
\cline { 2 - 6 } & Female & $45(52.3 \%)$ & $66(64.7 \%)$ & $67(59.8 \%)$ & $67(62.6 \%)$ \\
\hline \multirow{3}{*}{ Anxious } & Male & $51(32.7 \%)$ & $26(25.7 \%)$ & $17(16.5 \%)$ & $28(23 \%)$ \\
\hline \multirow{2}{*}{$\begin{array}{l}\text { So anxious that I sometimes break } \\
\text { out in a sweat or almost feel } \\
\text { physically sick }\end{array}$} & Female & $105(67.3 \%)$ & $75(74.3 \%)$ & $86(83.5 \%)$ & $94(77 \%)$ \\
\cline { 2 - 6 } & Female & $14(16.7 \%)$ & $5(9.8 \%)$ & $6(17.1 \%)$ & $2(6.9 \%)$ \\
\hline
\end{tabular}

Table 2: Percentage of patients DAS score

found to be relaxed, 96(41.7\%) little uneasy, 18(7.8\%) were tensed, $14(6.1 \%)$ were anxious and $2(0.9 \%)$ were very anxious. Wahid $\mathrm{U}$ et al ${ }^{25}$ reported that $43 \%$ of the respondents were relaxed. The present study reported that $25(6.5 \%)$ of the respondents were found to be relaxed and 156(40.6\%) were found to be anxious that their checkup would be unpleasant and painful.

The second question was related to how you would feel while waiting for the turn in dental office. Iqbal $\mathrm{M}^{24}$ reported that $74(32.2 \%)$ were found to be relaxed, 104(45.2\%) little uneasy, $31(13.5 \%)$ tensed, $19(8.3 \%)$ anxious and $2(0.9 \%)$ very anxious. Wahid $U$ et al ${ }^{25}$ reported that $44 \%$ of the respondents felt a little uneasy while waiting for their turn in dental office. The present study reported that $79(20.6 \%)$ felt a little uneasy, 102(26.6\%) tensed, 101(26.3\%) anxious and 51(13.3\%) very anxious. The anxiety and fear can be managed by placing Brochures, leaflets or handouts illustrating different dental procedures in the office. The ambiance of the waiting area should be made relaxing by playing ambient music while the patient waits their turn ${ }^{25}$.

Some people enclose painful encounters with the dental drill; thinking of the sound of the hand piece alone will make them anxious. The third question was related to patients' anxiety level regarding the drill ready for the treatment to be initiated. Iqbal $\mathrm{M}^{24}$ reported that $78(34.2 \%)$ felt a little uneasy, $76(33.3 \%)$ tense, $24(10.5 \%)$ anxious and $12(5.3 \%)$ very anxious. Wahid $\mathrm{U}$ et $\mathrm{al}^{25}$ reported that $28 \%$ felt little uneasy, $25 \%$ tensed. The present study reported that $92(24 \%)$ felt uneasy, $112(29.2 \%)$ tensed, 103(26.8\%) anxious and $35(9.1 \%)$ very anxious. Electric driven handpieces should be used as they produces less sound. Adequate maintenance of dental handpieces are mandatory for their proper working ${ }^{25}$.

The fourth question was related to the cleaning of the teeth. Wahid $U$ et al ${ }^{25}$ reported that $32 \%$ felt a little uneasy. Iqbal $\mathrm{M}^{24}$ reported that 80(35.1\%) felt a little uneasy, 49(21.5\%) tensed, $29(12.7 \%)$ anxious and $7(3.1 \%)$ very anxious. The present study reported that $88(22.9 \%)$ felt a little uneasy, 
$107(27.9 \%)$ tensed, 122)31.8\%) anxious and 29(7.6\%) very anxious. This could be managed by explaining the procedure and showing videos of the procedure in the waiting area. Effective counselling also helps a patients to calm down their fears ${ }^{25}$.

LIMITATIONS: Limitations of this study were small sample size.

\section{CONCLUSION:}

The present study concluded that female patients were found to be more anxious than males. Therefore dental surgeons should take adequate measures to manage level of dental anxiety amongst patients visiting dental teaching hospitals of Karachi.

\section{REFERENCES:}

1. Armfield JM. How do we measure dental fear and what are we measuring anyway? Oral Health Prev Dent. 2010;8:10715.

2. Ekanayake L, Dhamawardena D. Dental anxiety in patients seeking care at the university dental hospital in Srilanka. Community Dent Health 2003; 20:112-6.

3. Homson WM, Stewart JF, Carter KD, Spencer AJ. Dental anxiety among Australians. Int Dent J. 1996; 46(4):320-4.

4. Armfield JM, Stewart JF, Spencer AJ. The vicious cycle of dental fear: exploring the interplay between oral health, service utilization and dental fear. BMC Oral Health. 2007;7:1

5. Agras S, Sylvester D, Oliveau D. The epidemiology of common fear and phobia. Compr Psychiatry 1969; 10: 151-156.

6. CM Marya, S Grover, Jnaneshwar A, Pruthi N. Dental Anxiety among Patients Visiting a Dental Institute in Faridabad, India. West Indian Med J 2012; 61: 187- 190.

7. Mehrstedt M, John MT, Tönnies S, Micheelis W. Oral healthrelated quality of life in patients with dental anxiety. Community Dent Oral Epidemiol 2007; 35:357-63.

8. Crofts-Barnes NP, Brough E, Wilson KE, Beddis AJ, Girdler NM. Anxiety and quality of life in phobic dental patients. J Dent Res 2010; 89:302-6.

9. Mehboob, B., Khan, E., and Khan, M. Dental anxiety scale in exodontia patients. Journal of Khyber College of Dentistry 2011; 1(2): 66-70.

10. Faisal, S., Zehra, N., Hussain, M., Huzaifa Ali, H. J., and Faisal, A. (2015).Dental anxiety among patients attending public and private dental hospitals of Karachi. Journal of the Pakistan Dental Association 2015;24 (1): 46 - 51.

11. DG Kirova, DT Atanasov, CK Lalabonova, S Janevska. Dental anxiety in adults in Bulgaria. Folia Medica 2010; 52: 49-56.

12. Armfield JM, Spencer AJ, Stewart JF. Dental fear in Australia: who's afraid of the dentist? Aust Dent J. 2006; 51(1):78-85.

13. Hagglin C, Hakeberg M, Ahlqwist M, Sullivan M, Berggren $\mathrm{U}$. Factors associated with dental anxiety and attendance in middle-aged and elderly women. Community Dent Oral Epidemiol. 2000; 28:451-60.

14. Caltabiano M, Croker F, Page L, Sklavos A, Spiteri J, Hanrahan L, Choi R. Dental anxiety in patients attending a student dental clinic . BMC Oral Health 2018; 18(4): 2-8.
15. Z Morse. Dental anxiety is very high in the Republic of Kiribati. South Pac Stud 2007; 28:23-30.

16. Stabholz A, Peretz B. Dental anxiety among patients prior to different dental treatments .International dental journal. 1999; 49:90-4.

17. Armfield JM, Stewart JF, Spencer AJ. The vicious cycle of dental fear: exploring the interplay between oral health, service utilization and dental fear. BMC Oral Health. 2007; 7:1.

18. Newton JT, Buck DJ. Anxiety and pain measures in dentistry: a guide to their quality and application. The Journal of the American Dental Association 2000; 131: 1449-57.

19. McGrath C, Bedi R. The association between dental anxiety and oral health-related quality of life in Britain. Community Dent Oral Epidemiol. 2004; 32(1):67-72.

20. Kirova DG, Atanasov DT, Lalabonova CK, Janevska S. Dental anxiety in adults in Bulgaria. Folia Med 2010; 52(2):49-56.

21. Sohn W, Ismail A. regular dental visits and dental anxiety in an adult dentate population. J Am Dent Assoc.2005; 136:5866.

22. Anzar W, Afaq A, Baig QA. Assessment of dental anxiety in adults undergoing dental procedures in Dow International Dental College, J Dow University of Health Sciences 2017; 11(1): $2-5$.

23. Olszewska I, arow M, Gofroñ B, Paczyñska P. Assessment of dental anxiety level prior to dental treatment. Mag Stomatol 2000; 7-8:58-62.

24. Iqbal M. Frequency of anxiety related to dental procedures among professional students. Isra Medical Journal 2015; $7(1): 30-33$.

25. Wahid U, Amin M, Choudhry Z, Ahmed M. Dental anxiety level of patients presenting to operative dentistry department. Pakistan oral \& dental journal. 2015; 35(4): 675- 80.

26. Jafarzadeh M, Keshani F, Ghazavi Z, Keshani F. Reviewing the parental standpoint about origin of the dental fear in children referred to dentistry centers of Isfahan University of Medical sciences. Iran J Nurs Midwifery Res. 2011; 16(1):133139.

27. Stabholz A, Peretz B. Dental anxiety among patients prior to different dental treatments. International dental journal. 1999; 49:90-4.

28. Malvania EA, Ajithkrishnan CG. Prevalence and sociodemographic correlates of dental anxiety among a group of adult patients attending a dental institution in Vadodara city, Gujarat, India. Indian Journal of Dental Research. 2011; 22:179.

29. Udoye CI, Oginni AO, Oginni FO. Dental anxiety among patients undergoing various dental treatments in a Nigerian teaching hospital. J Contemp Dent Pract. 2005; 15(6):91-8.

30. Sardar KP, Raza ISSA, Shafi M. Dental anxiety level in patients attending dental outpatient department at Dow University of health sciences. J Pak Dent Assoc 2015; 24(3):145-151.

31. Humphris GM, Dyer TA, Robinson PG. The modified dental anxiety scale: UK general public population norms in 2008 with further psychometrics and effects of age. BMC Oral Health 2009; 26:9-20. 